\title{
Differences in the expression of microRNAs implicated in colorectal carcinogenesis and involved in the WNT signalling pathway in the macroscopically-normal epithelium of people at higher-risk of colorectal cancer
}

\author{
F. C. Malcomson ${ }^{1}$, N. D. Willis ${ }^{1}$, I. McCallum ${ }^{1}$, L. Xie ${ }^{1}$, S. Kelly $^{1}$, M. Bradburn ${ }^{1}$, \\ N. J. Belshaw ${ }^{2}$, I. T. Johnson ${ }^{2}$ and J. C. Mathers \\ ${ }^{1}$ Human Nutrition Research Centre, Institute for Ageing and Health, Newcastle University, Newcastle upon Tyne NE4 \\ 5PL, UK and ${ }^{2}$ Institute of Food Research, Norwich Research Park, Norfolk NR4 7UA, UK
}

People with ulcerative colitis (UC) or adenomatous polyps (adenomas) are at increased risk of colorectal cancer (CRC) ${ }^{(1)}$. Altered expression of microRNAs (miRNAs), small non-coding RNAs that regulate gene expression post-transcriptionally, has been observed in those with $\mathrm{UC}^{(2)}$ and adenomas ${ }^{(3)}$. Importantly, abnormally-expressed miRNAs contribute to the initiation and progression of $\mathrm{CRC}$ and are potential biomarkers for diagnosis and prognosis of this cancer ${ }^{(4)}$. This study aimed to investigate differences in the expression of a panel of miRNAs in the macroscopically-normal mucosa of people at higher-risk of CRC.

We quantified expression of 8 miRNAs that are (i) implicated in CRC, (ii) regulators of WNT signalling, a pathway frequently aberrantly activated in $\mathrm{CRC}^{(5)}$, and/or (iii) whose expression is altered by butyrate treatment in healthy participants $(n=56)$ and in patients at higher CRC risk with quiescent UC $(n=26)$ or history of adenomatous polyps $(n=12)$. RNA was isolated from mucosal biopsies of macroscopically-normal tissue collected at $10 \mathrm{~cm}$ from the anal verge. cDNA was synthesised by reverse transcription and used to quantify the expression of $m i R-17, m i R-19 a, m i R-19 b, m i R-20 a$, miR-25, miR-93, miR-106b and miR-424 by quantitative PCR. For normally distributed data, the ANOVA General Linear Model was used to compare miRNA expression between the 3 risk groups, adjusting for age, sex and endoscopy procedure as covariates. Where data were not normally distributed, the nonparametric Kruskal-Wallis test was used.

Table 1. Median and range values for miRNA expression expressed as adjusted copies $\left(2^{-\Delta \mathrm{Ct}} \times 1,000\right)$ relative to the geometric mean of $R N U 6$ and $S N O R D 68$ controls.

\begin{tabular}{|c|c|c|c|c|c|c|}
\hline \multirow[b]{2}{*}{ miRNA } & \multicolumn{2}{|c|}{ Healthy Participants } & \multicolumn{2}{|c|}{ Polyp Patients } & \multicolumn{2}{|c|}{ UC Patients } \\
\hline & Median & Range & Median & Range & Median & Range \\
\hline$m i R-17$ & 129 & $69-401$ & 125 & $52-179$ & 118 & $75-153$ \\
\hline$m i R-19 a$ & 97 & $17-1728$ & 156 & 19-751 & 89 & $29-464$ \\
\hline $\operatorname{miR}-19 b$ & 69 & $15-3809$ & 91 & $16-437$ & 82 & $25-279$ \\
\hline$m i R-20 a$ & $333^{*}$ & $107-1550$ & $308 *$ & $152-424$ & $279 *$ & $181-379$ \\
\hline$m i R-25$ & 116 & 13-9987 & 69 & $34-129$ & 78 & $50-153$ \\
\hline$m i R-93$ & 77 & $10-1102$ & 70 & $32-125$ & 68 & $47-114$ \\
\hline$m i R-106 b$ & 164 & $61-5548$ & 162 & $77-242$ & 144 & $109-180$ \\
\hline$m i R-424$ & $32 * *$ & $9-1145$ & $24 * *$ & $7-50$ & $69^{* *}$ & $17-137$ \\
\hline
\end{tabular}

** $p<0 \cdot 01$ and $* p<0 \cdot 1$ for differences between risk groups (Kruskal-Wallis test)

We observed significantly higher $m i R-424$ expression $(p<0 \cdot 01)$, a miRNA reported to be increased in CRCs ${ }^{(6)}$, and reduced $m i R-20 a$ expression $(p=0.055)$ in participants with quiescent UC (Table 1). miR-20a expression also appears to be reduced in polyp patients. Alterations in miRNA expression may be detected in the healthy tissue of people at higher-risk of CRC and may represent very early molecular changes contributing to the progression from normal mucosa to carcinoma.

This study was funded by the BBSRC (BB/H005013/1). Ethical approval for the study was granted on $10^{\text {th }}$ December 2009 (REC No. 09/H0907/77).

1. Itzkowitz SH \& Yio X (2004) Am J Physiol Gastrointest Liver Physiol 287, G7-17.

2. Coskun M, Bjerrum JT, Seidelin JB (2012) World J Gastroenterol 18, 4629-4634.

3. Oberg AL, French AJ, Sarver AL et al. (2011) PLoS One 6, e20465.

4. Schetter AJ, Okayama H, Harris CC (2012) Cancer J 18, 244-252.

5. Bienz M \& Clevers H (2000) Cell 103, 311-320.

6. Wang YX, Zhang XY, Zhang BF et al. (2013) J Dig Dis 11, 50-54. 